\title{
Dust Retention Ability of Plants as a Factor Improving Environment Air
}

\author{
Tazhimamat Erkebaev1, Kursantbek Attokurov1, Absamat Sattarov², Minavar Shaimkulova3, \\ Nurgazy Orozaliev", Tashbolot Erkebaev5, Elida Topchubaeva6, Nurgul Kaparova7, \\ Zhypargul Abdullaeva ${ }^{8^{*}}$ (1)
}

${ }^{1}$ Department of Botany, General Biology Disciplines and Teaching Methodic, Osh State University, Osh, Kyrgyzstan

${ }^{2}$ Department of Histology and Pathologic Anatomy, Osh State University, Osh, Kyrgyzstan

${ }^{3}$ Department of Elementary Education Theory and Teaching Methodic, Osh State University, Osh, Kyrgyzstan

${ }^{4}$ Medical College, Osh State University, Osh, Kyrgyzstan

${ }^{5}$ Department of Zoology and Ecology, Osh State University, Osh, Kyrgyzstan

${ }^{6}$ Department of General Biochemistry and Clinical Pathology, Medical Faculty, Osh State University, Osh, Kyrgyzstan

${ }^{7}$ Department of Elementary Education Theory and Methodic, Osh State University, Osh, Kyrgyzstan

${ }^{8}$ Science and Research Department, Osh State University, Osh, Kyrgyzstan

Email: ^jypar.science@oshsu.kg

How to cite this paper: Erkebaev, T., Attokurov, K., Sattarov, A., Shaimkulova, M., Orozaliev, N., Erkebaev, T., Topchubaeva, E., Kaparova, N. and Abdullaeva, Z. (2021) Dust Retention Ability of Plants as a Factor Improving Environment Air. American Journal of Plant Sciences, 12, 187-198. https://doi.org/10.4236/ajps.2021.122011

Received: December 30, 2020

Accepted: February 22, 2021

Published: February 25, 2021

Copyright $\odot 2021$ by author(s) and Scientific Research Publishing Inc. This work is licensed under the Creative Commons Attribution International License (CC BY 4.0).

http://creativecommons.org/licenses/by/4.0/

\begin{abstract}
It is well known that air in industrial cities contains a significant amount of dust particles, smoke, and toxic gases. The increased number of vehicles has a direct impact on air quality resulting in the emission of exhaust gases, and the increase of dust concentration in air. In this article, we are describing the dust retention ability of plants depending on their leaf structure. Plant species were classified into three groups according to their dust-holding capacities. Dust retaining ability of plant species in conditions of high, average and low dust conditions described.
\end{abstract}

\section{Keywords}

Dust Retention, Leaf Morphological Structure, Rough Leaf Surface, Smooth Leaf Surface, High Dust Retention Capacity, Average Dust Retention, Low Dust Retention Capacity

\section{Introduction}

Green plants play an exceptionally important role against air pollution [1] [2]. They are functioning as a "living filter" for trapping smoke, dust, soot, and soot, as their leaves absorb many toxic substances. Therefore, one hectare of green plant species cleans about 18 million $\mathrm{m}^{3}$ of air per year [3]. Primary mechanisms by which vegetation is considered to improve air quality are dispersion involving 
the transportation and dilution of pollutants from the pollutant source; and deposition, the process by which pollutants are deposited on the plants solid surfaces by reducing pollutants atmospheric concentrations [4]. Leaf microstructure is characterized by groove area and trichomes which are significantly influenced dust deposition comparing to leaves with the smooth structure; foliar surface morphology has direct effects on the dust capture by leaves which is consistent with a degree of leaf roughness and the number of trichomes in the upper and lower epidermis of a leaf determined the dust retention capacity. Leaf roughness quantified by the groove area ratio to the total leaf area in percentage as shown in the following equation [5]:

$$
\text { Groove area ratio }=A_{G} / A_{L} \times 100 \%
$$

here, $A_{G}$ is a groove area $\left(\mu \mathrm{m}^{2}\right)$ and $A_{L}$ is the total leaf area $\left(\mu \mathrm{m}^{2}\right)$.

In winter, dust accumulates under the canopy of parklands by $8 \%-30 \%$ more than in open areas [6], which has been experimentally proven for one hectare of green plant territory per year filtering out $50-70$ tons of dust from the air, reducing its concentration by $30 \%-40 \%$ [7].

The ability of growing plants to retain dust and particulate substances is depending on their species, leaf and branch density, and surface properties related to the microstructure [8], and explained by several factors. Firstly, the biological processes taking place in plants allow assimilation of gases, binding, and deposition in the assimilation apparatus of leaves or even move along the branches [8] [9].

Secondly, the physical and mechanical properties of leaf surfaces and branches can retain and deposit dust. In this case, the dust deposition capacity depends on the total quantity of the leaf surface area and the structure of the leaf surface. Under equal conditions, rough, folded, drooping, and sticky leaves retain more dust comparing to smooth leaves [10]. For example, 2.3 times more dust settles on the elm leaves comparing to the poplar leaves, and 1.5 times more than on white ash leaves [11].

The third factor is explained by the ability of plantations to influence the wind regime in a green area. Above a warmer open space, the air rises upward, while cool air from the green mass rushes to replace the one that has risen. Therefore, a horizontal airflow arises, contributing to the ventilation of the territory, and the dispersion of harmful impurities, a decrease in their concentration [12]. Figure 1 shows the dust-removing capacity for plant species one adult tree during the growing season: pinnately branched elm removes from the air $28 \mathrm{~kg}$ of dust, rough elm $23 \mathrm{~kg}$, horse chestnut $16 \mathrm{~kg}$, field maple $20 \mathrm{~kg}$, and ash left maple $33 \mathrm{~kg}$, common ash $27 \mathrm{~kg}$, poplar more than $18 \mathrm{~kg}$ [13], 20 times more dust [14]. Additionally, it was shown that during growing season average dust concentration in the open area is $42.2 \%$ higher compared with the area under the trees. Referring to the dustproof properties of various rocks, it was indicated that quantitative scales of dustiness are depending on the square of the plant growing area and the density of plantings [15]. 


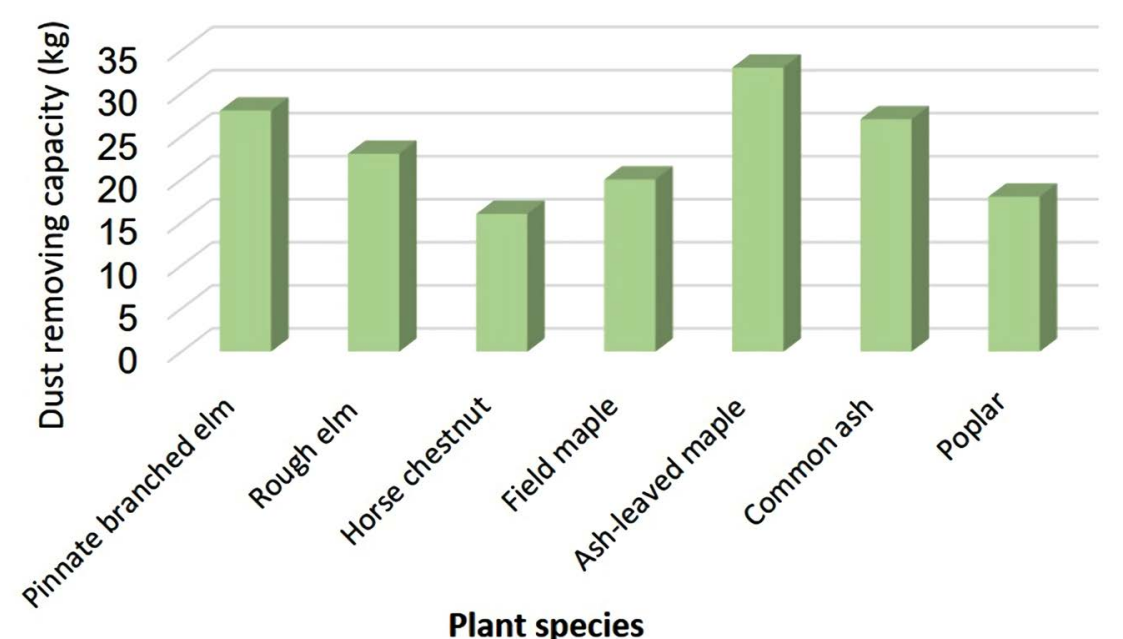

Figure 1. Dust removing capacities in a growing season for various plant species.

According to research carried out in Central Asia [11] [23], it was found that plants with groove leaves have the most pronounced dust-protective properties, especially in spring, when crowns are fully developed, which result in the reduction of dust concentration by $33 \%$ - 39\%. Effectiveness of dust retention capacity depends on the type of planting and crown density, as mixed plantings retain dust by $9 \%$ - $17 \%$ more than one type planting; and in vertical crown density, the dust retention capacity is $18 \%-20 \%$ more in contrast to horizontal crown density.

As a result, green spaces assorted and positioned appropriately can provide good protection against dust, smoke, and harmful gases in the air. In connection with the above statements, we have reviewed the dust-holding capacity of 17 plant species, which are widely used trees and shrub plants. The dust retention capacity was determined by washing the leaves according to the method described in the reference [12], where the number of suspended solids was expressed in grams per $1 \mathrm{~m}^{2}$ of the leaf surface.

It is also important to highlight that, the clearly expressed properties of the leaves in studied plant species were noted to keep different amounts of dust on their surface under the same dust conditions. As a consequence, on the needles of Junipers virginiana, which has the maximum dust-retaining ability comparing to other species, dust was deposited 2 times more than on the leaves of Plotinus orientalis, 4 times more than on Aesculus hippocastanum, and 8 times more than the leaves of Acer campestre. The dust-holding capacity diversity of various leaf types were also noted previously [12] [16] [23].

\section{Research Methods}

Study performed in 2015, in the Osh city; dust-retaining ability of plant species in conditions of high dustiness first measurement carried out in Masalieva avenue. Second measurement carried out in the botanical garden with average dustiness conditions. The species studied by us can be divided into three groups ac- 
cording to the maximum dust-holding capacity [17]: the first group includes species with a high dust-holding capacity is over $8 \mathrm{~m} / \mathrm{m}^{2}$ : Juniper us Virginian, Biota oriental is, Ulmus pumila, Guercus Robur, and Platanus orientalis.

The second group includes species with an average dust-holding capacity from $3-8 \mathrm{mg} / \mathrm{m}^{2}$ such as Catalpa speciosa, Finus palasiana, Aesculus hippocastanum, Juglans regia, Gleditschia triacanthos, psedoacacia, Sophora japonica, Fraxinus exselsior, Populus nigra and Salix alba.

The third group includes species with a low dust-holding capacity below 3 $\mathrm{mg} / \mathrm{m}^{2}$, such as: Cercis canadensis, Albizzia julibrissin, Betula pendula, and Acer campestre. From the studied fruit crops, apple, plum and cherry had an average, and apricot low dust-holding capacities. The dust retention capacity was determined by washing the leaves according to the Gusev method [12]. Here amount of solid substance mass was expressed in grams per $1 \mathrm{~m}^{2}$ of leaf surface. Square in $\mathrm{cm}^{2}$ was calculated for one leaf of each studied plant species. Average value of leaf surface square was determined from 10 leafs of one plant. Next, we determined the specific dust-retention capacity of leaves per $1 \mathrm{~cm}^{2}$ by using an average area of one leaf according to the following formula [18]:

$$
S d=\mathrm{m} / \mathrm{s}
$$

here, $S d$ is the specific dust-retention capacity for one leaf, m means dust mass retained by one leaf, $s$ is an average square of one leaf.

Measurement values $t$ were shown in Tables 1-4, meaning difference error according to students criteria obtained from the following equation [19]:

$$
t=\frac{\bar{X}_{E}-\bar{X}_{K}}{\sqrt{m_{E}^{2}+m_{K}^{2}}}
$$

The differences reliability expressed by obtained value $(t)$ comparing with the tabular value at a $5 \%$ significance level $(t=0.05)$ with the number of freedom degrees $t=m_{E}+m_{K}$, where $m_{E}$ and $m_{K}$ are the total number of individual results in the experimental and control groups, respectively.

\section{Results and Discussions}

The species of the first group are characterized by a special structure of the surface of leaves and needles. For instance, the needles of Juniperus virginian and Biota orientalis (Figure 2) have numerous scaly leaves, due to which its surface increases and folds form, which contribute to the strong retention of dust. The leaves of Platanus orientalis are characterized by planted hydrodes that secrete a sticky substance [20]. Ulmus pumila leaves have a shallow surface (Figure 3). The listed features of the structure of the surface of leaves and needles make it possible for these plants to retain more dust. The accumulated dust is difficult to wash off and is not blown away by the wind. Indications that rough leaves retain more dust than smooth ones found by many authors [11] [21]. Platanus orientalis (Figure 4) and Catalpa speciosa (Figure 5) have high dust-retaining properties, which have sticky or pubescent leaves. 


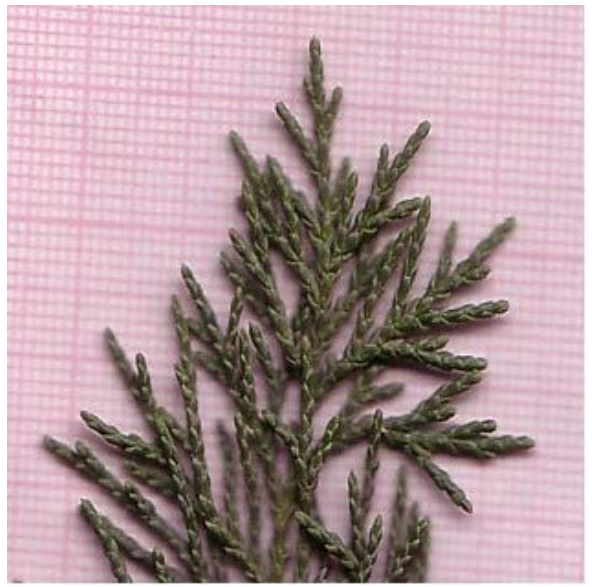

(a)

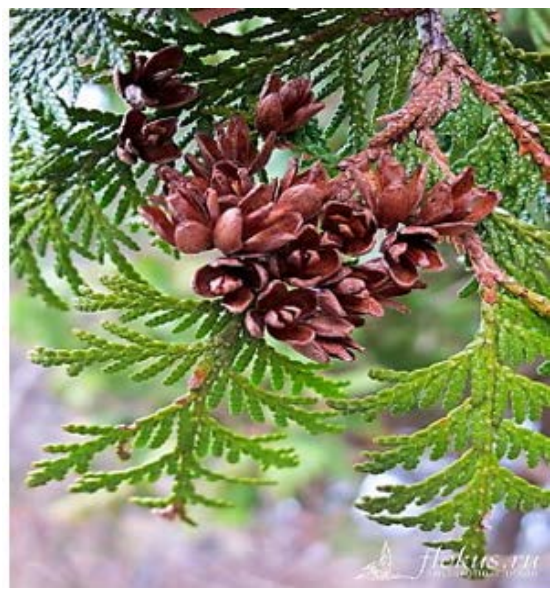

(b)

Figure 2. Leaf structures: (a) Juniperus virginian, (b) Biota orienta.

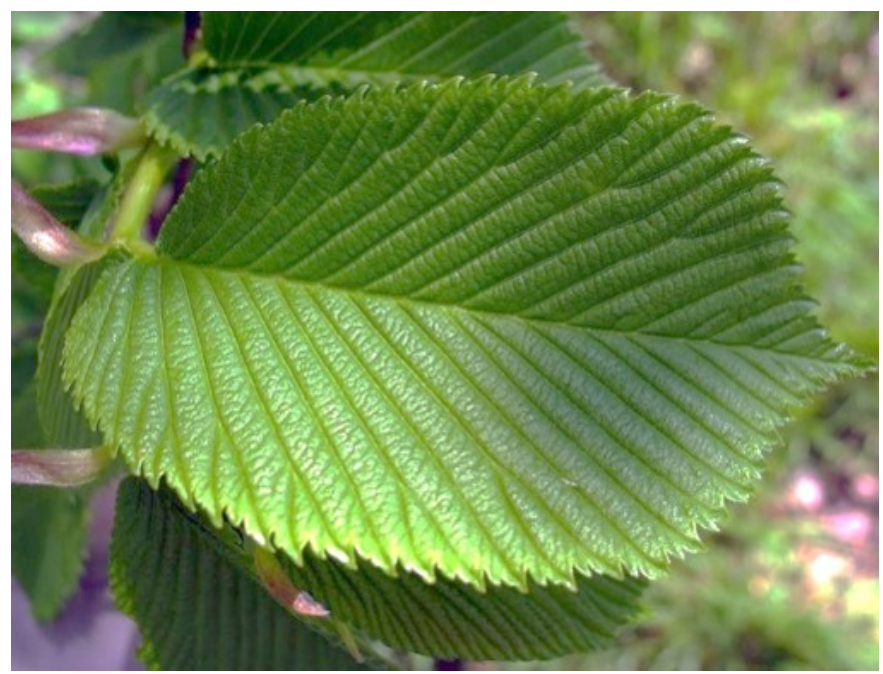

Figure 3. Structure of the UImus pumila leaf.

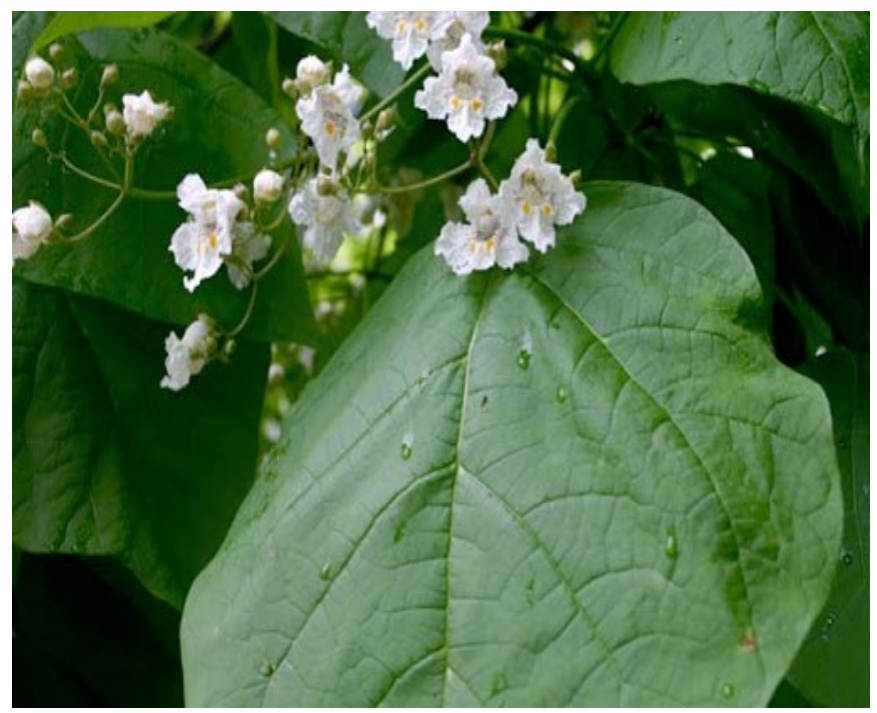

Figure 4. Structure of the Platanus orientalis leaf. 


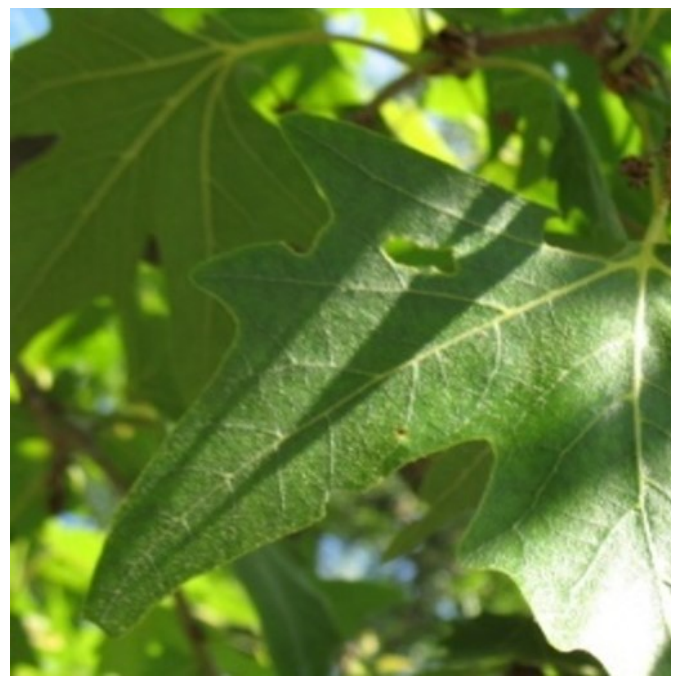

Figure 5. Structure of the Catalpa speciosa leaf.

Table 1. Dust-retaining ability of the studied plant species in conditions of high dustiness city and streets, $\mathrm{g} / \mathrm{m}^{2}$, first measurement.

\begin{tabular}{|c|c|c|c|c|}
\hline Kind & June & July & August & September \\
\hline Juniperus virginiana & $9.93 \pm 0.73$ & $15.50 \pm 1.12$ & $15.92 \pm 1.14$ & $16.24 \pm 1.42$ \\
\hline Biota orientalis & $9.15 \pm 0.65$ & $14.12 \pm 1.19$ & $15.23 \pm 1.06$ & $16.00 \pm 1.24$ \\
\hline Guercus Robur & $4.13 \pm 0.25$ & $6.42 \pm 0.52$ & $8.10 \pm 0.74$ & $8.35 \pm 0.71$ \\
\hline Ulmus pumila & $3.73 \pm 0.30$ & $6.61 \pm 0.55$ & $7.06 \pm 0.42$ & $8.59 \pm 0.68$ \\
\hline Platanus orientalis & $4.43 \pm 0.21$ & $6.52 \pm 0.43$ & $7.81 \pm 0.79$ & $8.70 \pm 0.65$ \\
\hline Catalpa speciosa & $2.35 \pm 0.15$ & $3.08 \pm 0.29$ & $3.67 \pm 0.19$ & $4.70 \pm 0.3$ \\
\hline Finus pallasiana & $3.00 \pm 0.21$ & $3.03 \pm 0.21$ & $4.57 \pm 0.17$ & $4.74 \pm 0.15$ \\
\hline Juglans regia & $3.65 \pm 0.31$ & $4.12 \pm 0.22$ & $4.41 \pm 0.66$ & $4.81 \pm 0.18$ \\
\hline Aesculus hippocastanum & $3.13 \pm 0.35$ & $4.40 \pm 0.39$ & $4.50 \pm 0.21$ & $4.60 \pm 0.23$ \\
\hline Sophora japonica & $2.13 \pm 0.32$ & $2.02 \pm 0.16$ & $2.38 \pm 0.11$ & $3.67 \pm 0.17$ \\
\hline Gleditschia triacanathos & $2.30 \pm 0.11$ & $2.12 \pm 0.12$ & $3.40 \pm 0.20$ & $3.64 \pm 0.29$ \\
\hline Populus nigra & $1.94 \pm 0.10$ & $2.69 \pm 0.15$ & $3.05 \pm 0.40$ & $3.56 \pm 0.13$ \\
\hline Fraxinus excelsior & $2.72 \pm 0.17$ & $3.11 \pm 0.22$ & $3.40 \pm 0.18$ & $3.54 \pm 0.23$ \\
\hline Salix alba & $2.65 \pm 0.21$ & $2.35 \pm 0.11$ & $2.30 \pm 0.15$ & $3.31 \pm 0.21$ \\
\hline Robinia pseudoacacia & $2.75 \pm 0.19$ & $2.06 \pm 0.27$ & $2.93 \pm 0.12$ & $3.04 \pm 0.14$ \\
\hline Albizzia julibrissin & $1.76 \pm 0.15$ & $2.63 \pm 0.19$ & $2.77 \pm 0.17$ & $2.94 \pm 0.19$ \\
\hline Acer campestre & $1.70 \pm 0.10$ & $1.50 \pm 0.09$ & $2.54 \pm 0.13$ & $2.76 \pm 0.17$ \\
\hline Betula pendula & $1.30+0.12$ & $1.11+0.18$ & $1.25+0.09$ & $1.94+0.11$ \\
\hline Cercis canadensis & $1.10+0.07$ & $1.13+0.11$ & $1.26+0.21$ & $1.78+0.15$ \\
\hline \multicolumn{5}{|l|}{ Fruit crops } \\
\hline Apple & $2.47 \pm 0.16$ & $2.96 \pm 0.21$ & $3.65 \pm 0.31$ & $4.15 \pm 0.29$ \\
\hline Cherry & $2.96 \pm 0.18$ & $3.02 \pm 0.25$ & $3.47 \pm 0.24$ & $3.93 \pm 0.32$ \\
\hline Plum & $2.30 \pm 0.23$ & $2.90 \pm 0.19$ & $311 \pm 0.21$ & $3.25 \pm 0.28$ \\
\hline Apricot & $3.15 \pm 0.14$ & $2.35 \pm 0.17$ & $2.58 \pm 0.15$ & $2.93 \pm 0.18$ \\
\hline
\end{tabular}


Table 2. Dust-retaining ability of the studied plant species in conditions of high dustiness, city streets, $\mathrm{g} / \mathrm{m}^{2}$, second measurement (t $0.05 \geq 2.31$ ).

\begin{tabular}{|c|c|c|c|c|c|}
\hline Kind & June & July & August & September & $\mathrm{t}$ \\
\hline Juniperus virginiana & $11.41 \pm 0.91$ & $14.53 \pm 1.11$ & $14.76 \pm 1.30$ & $15.93 \pm 1.01$ & 0.18 \\
\hline Biota orientalis & $9.76 \pm 0.65$ & $12.95 \pm 0.84$ & $12.88 \pm 0.69$ & $13.33 \pm 0.87$ & 1.77 \\
\hline Guercus Robur & $4.46 \pm 0.33$ & $6.68 \pm 0.49$ & $7.76 \pm 0.55$ & $8.90 \pm 0.51$ & 0.63 \\
\hline Ulmus pumila & $3.11 \pm 0.27$ & $4.02 \pm 0.39$ & $5.86 \pm 0.41$ & $8.02 \pm 0.43$ & 0.71 \\
\hline Platanus orientalis & $5.93 \pm 0.43$ & $6.09 \pm 0.64$ & $6.24 \pm 0.43$ & $6.53 \pm 0.61$ & 2.43 \\
\hline Catalpa speciosa & $3.61 \pm 0.23$ & $3.87 \pm 0.32$ & $4.20 \pm 0.37$ & $4.46 \pm 0.51$ & 0.41 \\
\hline Finus pallasiana & $3.23 \pm 0.16$ & $3.58 \pm 0.29$ & $4.11 \pm 0.44$ & $4.35 \pm 0.49$ & 1.50 \\
\hline Juglans regia & $2.72 \pm 0.21$ & $2.62 \pm 0.16$ & $3.60 \pm 0.11$ & $3.87 \pm 0.21$ & 3.48 \\
\hline Aesculus hippocastanum & $3.03 \pm 0.13$ & $3.21 \pm 0.19$ & $3.36 \pm 0.15$ & $4.31 \pm 0.22$ & 0.96 \\
\hline Sophora japonica & $2.21 \pm 0.20$ & $2.29 \pm 0.11$ & $2.34 \pm 0.20$ & $3.02 \pm 0.14$ & 3.00 \\
\hline Gleditschia triacanathos & $2.50 \pm 0.19$ & $2.64 \pm 0.14$ & $2.47 \pm 0.21$ & $3.49 \pm 0.17$ & 0.48 \\
\hline Populus nigra & $2.96 \pm 0.23$ & $2.96 \pm 0.12$ & $3.11 \pm 0.16$ & $3.40 \pm 0.15$ & 0.80 \\
\hline Fraxinus excelsior & $2.02 \pm 0.13$ & $2.22 \pm 0.17$ & $3.05 \pm 0.16$ & $3.09 \pm 0.20$ & 1.50 \\
\hline Salix alba & $2.93 \pm 0.17$ & $2.40 \pm 0.13$ & $2.76 \pm 0.21$ & $3.11 \pm 0.15$ & 1.60 \\
\hline Robinia pseudoacacia & $1.65 \pm 0.11$ & $2.30 \pm 0.16$ & $2.99 \pm 0.21$ & $2.24 \pm 0.18$ & 0.21 \\
\hline Albizzia julibrissin & $1.25 \pm 0.10$ & $1.68 \pm 0.11$ & $1.74 \pm 0.17$ & $1.44 \pm 0.15$ & 5.00 \\
\hline Acer campestre & $1.16 \pm 0.11$ & $1.52 \pm 0.13$ & $1.39 \pm 0.15$ & $1.44 \pm 0.19$ & 3.95 \\
\hline Betula pendula & $1.23 \pm 0.15$ & $1.59 \pm 0.54$ & $1.09 \pm 0.10$ & $0.96 \pm 0.09$ & 6.30 \\
\hline Cercis canadensis & $1.02-0.09$ & $0.92-0.10$ & $1.48-0.07$ & $0.96-0.08$ & 1.87 \\
\hline \multicolumn{6}{|l|}{ Fruit crops } \\
\hline Apple & $3.15 \pm 0.21$ & $3.30 \pm 0.23$ & $3.70 \pm 0.32$ & $4.05 \pm 0.25$ & 0.7 \\
\hline Cherry & $2.93 \pm 0.23$ & $3.46 \pm 0.30$ & $3.65 \pm 0.27$ & $3.76 \pm 0.30$ & 0.89 \\
\hline Plum & $2.63 \pm 0.17$ & $2.76 \pm 0.19$ & $3.04 \pm 0.17$ & $3.40 \pm 0.42$ & 1.89 \\
\hline Apricot & $3.20 \pm 0.21$ & $2.15 \pm 0.15$ & $2.65 \pm 0.19$ & $2.80 \pm 0.18$ & 2.6 \\
\hline
\end{tabular}

Table 3. Dust-retaining ability of the studied plant species in low dust conditions, $\mathrm{g} / \mathrm{m}^{2}$, first measurement (t $0.05 \geq 2.31)$.

\begin{tabular}{ccccc}
\hline Kind & June & August & September & t \\
\hline Juniperus virginiana & $2.44 \pm 0.21$ & $3.52 \pm 0.45$ & $5.08 \pm 0.32$ & 21.18 \\
Biota orientalis & $3.48 \pm 0.42$ & $4.08 \pm 0.31$ & $5.42 \pm 0.44$ & 8.02 \\
Guercus Robur & $4.63 \pm 0.49$ & $4.43 \pm 0.37$ & $4.57 \pm 0.53$ & 4.29 \\
Ulmus pumila & $3.43 \pm 0.24$ & $3.60 \pm 0.42$ & $3.72 \pm 0.83$ & 6.51 \\
Platanus orientalis & $2.46 \pm 0.22$ & $2.99 \pm 0.38$ & $3.06 \pm 0.38$ & 7.52 \\
Catalpa speciosa & $1.94 \pm 0.12$ & $2.01 \pm 0.13$ & $2.44 \pm 0.18$ & 6.46 \\
Finus pallasiana & $1.01 \pm 0.13$ & $1.83 \pm 0.15$ & $1.91 \pm 0.12$ & 16.65 \\
Juglans regia & $0.96 \pm 0.22$ & $1.43 \pm 0.13$ & $1.90 \pm 0.22$ & 10.39 \\
\hline
\end{tabular}




\section{Continued}

\begin{tabular}{ccccc}
\hline Aesculus hippocastanum & $2.11 \pm 0.19$ & $2.46 \pm 0.16$ & $2.54 \pm 0.19$ & 2.32 \\
Sophora japonica & $1.22 \pm 0.10$ & $1.32 \pm 0.17$ & $2.74 \pm 0.21$ & 3.52 \\
Gleditschia triacanathos & $0.72 \pm 0.04$ & $1.69 \pm 0.08$ & $1.92 \pm 0.11$ & 3.73 \\
Fraxinus excelsior & $0.75 \pm 0.09$ & $1.42 \pm 0.09$ & $1.85 \pm 0.12$ & 4.82 \\
Robinia pseudoacacia & $0.98 \pm 0.10$ & $1.23 \pm 0.09$ & $1.58 \pm 0.11$ & 8.59 \\
Albizzia julibrissin & $0.88 \pm 0.17$ & $1.15 \pm 0.10$ & $1.56 \pm 0.09$ & 6.27 \\
Acer campestre & $0.54 \pm 0.04$ & $0.95 \pm 0.04$ & $1.42 \pm 0.05$ & 7.44 \\
Betula pendula & $0.57 \pm 0.04$ & $0.94 \pm 0.05$ & $1.09 \pm 0.04$ & 7.73 \\
Cercis canadensis & $0.42 \pm 0.03$ & $0.75 \pm 0.05$ & $1.06 \pm 0.03$ & 5.14 \\
\hline
\end{tabular}

Note: $\mathrm{t}$ is the reliability of differences in maximum values in conditions of high dust and low dust.

Table 4. Dust-retaining ability of the studied plant species in low-dust conditions (Botanical garden), $\mathrm{g} / \mathrm{m}^{2}$, second measurement (t $0.05 \geq 2.31$ ).

\begin{tabular}{|c|c|c|c|c|}
\hline Kind & June & August & September & $\mathrm{t}$ \\
\hline Juniperus virginiana & $3.42 \pm 0.19$ & $3.96 \pm 0.37$ & $4.17 \pm 0.39$ & 1.82 \\
\hline Biota orientalis & $3.27 \pm 0.24$ & $3.47 \pm 0.34$ & $4.45 \pm 0.47$ & 1.60 \\
\hline Guercus Robur & $3.72 \pm 0.43$ & $4.08 \pm 0.41$ & $4.49 \pm 0.32$ & 0.13 \\
\hline Ulmus pumila & $2.95 \pm 0.15$ & $3.01 \pm 0.19$ & $3.22 \pm 0.21$ & 1.25 \\
\hline Platanus orientalis & $2.51 \pm 0.21$ & $2.66 \pm 0.31$ & $2.98 \pm 0.18$ & 0.19 \\
\hline Catalpa speciosa & $0.87 \pm 0.12$ & $2.04 \pm 0.14$ & $2.36 \pm 0.15$ & 0.35 \\
\hline Finus pallasiana & $1.31 \pm 0.10$ & $1.53 \pm 0.11$ & $1.64 \pm 0.11$ & 1.68 \\
\hline Juglans regia & $6.80 \pm 0.06$ & $1.12 \pm 0.09$ & $1.61 \pm 0.15$ & 1.11 \\
\hline Aesculus hippocastanum & $1.97 \pm 0.13$ & $2.13 \pm 0.22$ & $2.43 \pm 0.11$ & 0.50 \\
\hline Sophora japonica & $1.21 \pm 0.11$ & $1.40 \pm 0.13$ & $2.67 \pm 0.17$ & 0.48 \\
\hline Gleditschia triacanathos & $0.96 \pm 0.06$ & $1.20 \pm 0.10$ & $1.65 \pm 0.11$ & 1.74 \\
\hline Fraxinus excelsior & $1.08 \pm 0.07$ & $1.14 \pm 0.09$ & $1.57 \pm 0.10$ & 1.75 \\
\hline Robinia pseudoacacia & $1.05 \pm 0.08$ & $1.21 \pm 0.10$ & $1.44 \pm 0.09$ & 1.00 \\
\hline Albizzia julibrissin & $0.73 \pm 0.04$ & $1.11 \pm 0.09$ & $1.21 \pm 0.13$ & 2.18 \\
\hline Acer campestre & $0.37 \pm 0.03$ & $0.49 \pm 0.03$ & $1.05 \pm 0.09$ & 3.63 \\
\hline Betula pendula & $0.28 \pm 0.03$ & $0.35 \pm 0.02$ & $0.87 \pm 0.04$ & 3.93 \\
\hline Cercis canadensis & $0.51 \pm 0.04$ & $0.63 \pm 0.04$ & $0.79 \pm 0.03$ & 6.43 \\
\hline
\end{tabular}

The leaves of the second and third group plant species have almost smooth leaf surfaces and do not have the above-mentioned properties, therefore not illustrated in this article. When comparing Tables 1-4 data it can be seen that with the different dustiness of air, the same species can accumulate a different amount of dust. Table 3 and Table 4 are presenting data on the dust-holding capacity in conditions of a botanical garden. Therefore, in a lower dust content (when air dust concentration is $0.2-0.3 \mathrm{mg} / \mathrm{m}^{3}$ ) the amount of dust accumu- 
lated is significantly less in plant species comparing to city and streets with a dust concentration of $0.5-0.0 .6 \mathrm{mg} / \mathrm{m}^{3}$ (t 2.31$)$. Here value $t$ is the meaning of reliability difference in maximum values in high and low dust conditions according to the Student criteria [19] [22].

It is interesting that in different groups, the change in the dust-retaining ability in conditions of different dustiness is far from the same. The greatest differences are observed in the species of the first group from 1.98 to 3.82 times, the least in the species of the third group from 1.13 to 1.87 times.

Thus, the higher the dust-holding capacity of a species, the more it increases in conditions of high dust content in the air. Both in conditions of high dustiness city and streets and conditions of low dustiness Botanical garden, the dynamics of dust accumulation in all species is similar. The amount of dust collected increases from June to September. At the same time, as can be seen from Table 2 second measurement.

In all the species of the third group and some species of the second group ( $\mathrm{Sa}$ lix alba and Rodinia pseudoacacia), the amount of dust on the leaf surface in September compared to August was lower, although the differences were insignificant. This is since measurements were preceded by light rain. As already mentioned, these species have a smooth leaf surface and even after a light rainfall, the amount of dust on them decreases even though, such precipitation did not affect the indicators of plant species of the first group. It is interesting that if, under conditions of high dust content, the September precipitation of the second measurement led to a decrease in the amount of retained dust in the species of the third group and some species of the second group, then under conditions of weaker dustiness, a decrease in these indicators is not observed (Table 2 and Table 4). This phenomenon can be explained by the fact that, under equal conditions, less dust is more strongly retained on the surface of the leaves.

It can be seen from Table 2 and Table 4 that both under conditions of high dustiness and under conditions of weaker dustiness, the data of both years for the species of the first and second groups do not differ significantly $(t<2.31)$, differ only in some species of the third group.

Thus, the species of the third group are the most labile in terms of dust-holding capacity, both in different years and even with small sediments. The third group include species with a low dust-holding capacity below $3 \mathrm{mg} / \mathrm{m}^{2}$ Cercis canadensis, Albizzia julibrissin, Betula pendula, and Acer campestre.

Of the fruit crops we have studied, apple, plum, and cherry have an average, and apricot has a low dust-holding capacity. The species of the first group are characterized by a special structure of the surface of leaves and needles. The needles of Juniperus virginian and Biota orienta is have numerous scaly leaves, due to which its surface increases and folds are formed, which contribute to the strong retention of dust.

The leaves of Ulmus pumila have a finely spaced surface (Figure 3), while the leaves of Platanus orientalis (Figure 4) are characterized by embedded guides, 
which secrete sticky substances [23].

The listed features of the structure of the surface of leaves and needles make it possible for these plants to retain more dust. The accumulated dust is difficult to wash off and is not blown away by the wind. Indications that rough leaves retain more dust than smooth ones are found by many authors [10] [20]. Catalpa speciosa (Figure 5) have high dust-retaining properties, which have sticky or pubescent leaves.

Table 3 and Table 4 show data on dust holding capacity in low dust conditions. When comparing the data shown in Tables 1-4, it can be seen that with different dust content in the air, the same species accumulate unequal amounts of dust.

More importantly, in different groups, the change in the dust-retaining ability in conditions of different dustiness is far from the same amount. The greatest differences were observed in the species of the first group (from 1.98 to 3.82 times), the least in the species of the third group, from 1.13 to 1.87 times (Table 2 and Table 4). Thus, the higher the dust-holding capacity of a species, the more it increases in conditions of high dust content in the air.

Both in conditions of high dustiness and conditions of low dustiness, the dynamics of dust accumulation in all species are similar. The amount of dust collected increases from June to September. At the same time, as can be seen from Table 2, in all species of the third group and some species of the second group (Salix alba and Rodinia pseudoacacia), the amount of dust on the leaf surface in September compared to August was lower, although the differences were insignificant. This is since light rain preceded the measurements in September.

\section{Conclusion}

To reduce the content of dust in the environment air in landscaped areas, the plant species of the first and second groups from the above classification were recommended for growing, such as Juniperus virginiana, Biota orientalis, Ulmus pumila, Guercus Robur, Platanus orientalis, Catalpa speciosa, Finus palasiana, Aesculus hippocastanum, Juglans regia, Gleditschia triacanthos, Robinia psedoacacia, Sophora japonica, Populus nigra, Salix alba, and Fraxinus excelsior. Notably, in the conditions of city streets, dustiness after precipitation in September second measurement showed a decrease in the amount of retained dust in the plant species of the third group and some species of the second group, then in conditions of weaker dustiness, a decrease in these indicators were not observed. This phenomenon can be explained by the fact that, under equal conditions, less dust is more strongly retained on the surface of the leaves.

\section{Conflicts of Interest}

The authors declare no conflicts of interest regarding the publication of this paper.

\section{References}

[1] Glinyanova, I. (2019) Small-Dispersed Dust Chemical Composition on the Leaves of 
Apricot Trees (Prunus armeniaca) in a Residential Area. E3S Web of Conferences, 138, Article ID: 01021. https://doi.org/10.1051/e3sconf/201913801021

[2] Manisalidis, I., Stavropoulou, E., Stavropoulos, A. and Bezirtzoglou, E. (2020) Environmental and Health Impacts of Air Pollution: A Review. Frontiers in Public Health, 8, 14. https://doi.org/10.3389/fpubh.2020.00014

[3] Bespaev, S.B. (1982) The Role of Plants in the Improvement of the Air Basin. Science, Alma-Ata, 3-8.

[4] Barwise, Y. and Kumar, P. (2020) Designing Vegetation Barriers for Urban Air Pollution Abatement: A Practical Review for Appropriate Plant Species Selection. NPJ Climate and Atmospheric Science, 3, Article No. 12. https://doi.org/10.1038/s41612-020-0115-3

[5] Chen, L., Liu, C. and Zhang, L. (2017) Variation in Tree Species Ability to Capture and Retain Airborne Fine Particulate Matter (PM2.5). Scientific Reports, 7, Article No. 3206. https://doi.org/10.1038/s41598-017-03360-1

[6] Zherebtsova, G.P. and Pokalov, O.N. (1988) Improving the Urban Environment Is a Means of Landscaping. Komkhoz RSFSR, Moscow, 61.

[7] Kolesnichenko, A.V. (1981) Forest Reclamation with the Basics of Forestry. Kolos, Moscow, $185 \mathrm{p}$.

[8] Kwak, M.J., Lee, J.K., Park, S., Kim, H., Lim, Y.J., Lee, K.-A., Son, J., Oh, C.-Y., Kim, I. and Woo, S.Y. (2020) Surface-Based Analysis of Leaf Microstructures for Adsorbing and Retaining Capability of Airborne Particulate Matter in Ten Woody Species. Forests, 11, 946. https://doi.org/10.3390/f11090946

[9] Kulagin, Y.Z. (1970) Gas Resistance of Woody Plants and Sulfur Accumulation in Leaves. Vegetation and Industrial Pollution, 7, 36-41.

[10] Durmushidze, S.V. (1977) Metabolism of Some Atmospheric Air Pollutants in Plants. Metsniereba, Tbilisi, 83.

[11] Polonskaya, L.S. (1970) Development of the Most Effective Designs for Landscape Categories of Forest Plantations of Green Zones in Cities of Central Asia. Scientific Report 1965-70, Tashkent, 64.

[12] Gusev, M.I. (1952) Dust-Holding Capacity of Leaves of Some Species of Tree Plantations. Sanitary and Hygiene, 6, 17-19.

[13] Erokhina, V.I., Zherebtsova, G.P. and Volftrub, T.I. (1987) Greening of Populated Areas. Stroyizdat, Moscow, 480 p.

[14] Bobokhidze, N.V. (1973) Landscaping of Protective Zones. Moscow Municipal Economy, 6, 33-37.

[15] Fedynskiy, I.V. and Dokuchaev, V.F. (1935) Dust-Proof Role of Green Spaces. Collected Works of the Sanitary Institute Named after Ersman. AN SSSR, Moscow, 22-26.

[16] Lunts, L.B. (1974) Urban Green Building. Stroizdat, Moscow, 275 p.

[17] Gorshkova, S.G. (1945) Robinia. SSSK Flora. AN SSSR, Moscow, Vol. 11, 305-326.

[18] Komarova, A. and Sadovnikova, L. (2018) Dust Collection Capacity of Woody and Shrubby Plants Leaves. All-Russian Competition of Educational and Research Works for Senior High School Students in Polytechnic, Natural, Mathematical Disciplines. For 9-11 Grade Students. Perm, 23 p.

[19] Kayimov, A.K. (1986) Biogeconoses of the Forest-Agricultural Landscape in Irrigated Lands. Fan, Tashkent, 132 p.

[20] Shishkin, B.K. (1963) Botanical Atlas. Agricultural Publishing, Leningrad, 403 p. 
[21] Voron, N.P. (1986) Influence of Cement Dust on Woody Vegetation. Forestry and Agroforestry, 72, 43-49.

[22] Lakin, G.G. (1990) Biometry. High Education, Moscow, 352 p.

[23] Myrzaibraimov, R.M. and Sopuev, A.S. (2016) Recommendations for the Implementation of the Computational and Analytical Part of Dissertations. Osh, 84 p. 